\title{
Seduepb
}

\section{II - Encontro dos Bispos do Nordeste}

II - Declaração dos Bispos do Nordeste

Dom Jaime Vieira Rocha

\section{SciELO Books / SciELO Livros / SciELO Libros}

ROCHA, D. J. V., org. Declaração dos Bispos do Nordeste. In: Sob os signos da Esperança e da responsabilidade social: anais do I e II Encontros dos Bispos do Nordeste (Campina Grande, 1956 | Natal, 1959) [online]. Campina Grande: EDUEPB, 2016, pp. 311-323. ISBN: 978-85-7879-485-9. Available from: doi: 10.7476/9788578794859.0011. Also available in ePUB from: http://books.scielo.org/id/c6ykx/epub/rocha-9788578794859.epub.

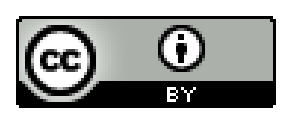

All the contents of this work, except where otherwise noted, is licensed under a Creative Commons Attribution 4.0 International license.

Todo o conteúdo deste trabalho, exceto quando houver ressalva, é publicado sob a licença Creative Commons Atribição 4.0. 


\section{II \\ Declaração dos Bispos do Nordeste}

NATAL, 26 DE MAIO DE 1959

Em seu II Encontro (Natal, Rio Grande do Norte, 24 a 26 de maio de 1959) os Bispos do Nordeste, depois de três dias de orações e estudos, empreendidos por expressa convocação da Exma. Comissão Central da Conferência Nacional dos Bispos do Brasil, com aprovação plena da Exma. Nunciatura Apostólica, e realizados com a ajuda de técnicos dos vários Órgãos Federais e Estaduais que atuam no Nordeste, chegaram às seguintes Afirmações, Conclusões, Sugestões e Votos:

\section{I - Afirmações}

1. Afirmações que todos nós, Bispos da Santa Igreja, temos bem presente a missão que Deus nos confiou, de ordem sobrenatural e de destinação eterna; mas tendo de agir não junto puros espíritos, mas a criatura humanas, de corpo e alma, e lembrados da repercussão, sobre a alma, de tudo o que atinge o corpo, também afirmamos o nosso direito e dever de interessar-nos pela situação temporal do povo, sobretudo em área subdesenvolvida como o Nordeste.

De nossa parte esse interesse traduz amor ao rebanho que nos foi entregue pela Providência e salvaguarda da paz social, comprometida pelo grave desnivelamento econômico entre nossa região e a região centro-sul.

2. Afirmamos nosso júbilo ao ver surgir a Operação Nordeste, aplicação, dentro de nossas fronteiras, dos princípios que animam a Operação Pan-Americana cuja bandeira o Brasil, em hora feliz, desfraldou.

3. Afirmamos a necessidade de ver o planejamento econômico, elaborado para o Nordeste, completado por aspectos humanos e 
por implicações sociais, abem do próprio planejamento econômico, para que não se torne inhumano e irreal.

4. Afirmamos, dentro desse pensamento, e baseados nas Conclusões dos Grupos de Estudos do Encontro, que o desenvolvimento econômico do Nordeste:

a) só atingirá sua eficiência plena se se apoiar no esforço consciente e voluntário das forças atuantes de toda a comunidade, para o que se torna urgente a preparação, em todos os seus níveis, de líderes, especializados em modernas técnicas de organização comunitária, tais como a promoção do cooperativismo, do serviço de extensão rural e de outros processos de educação de base;

b) supõe que a agricultura regional mereça tratamento igualitário, sob todos os aspectos, ao que se vier a dar ao desenvolvimento industrial;

c) exige medidas não só relativas a um melhor nível alimentar mas também providencias que visem à saúde pública, tendo-se em vista que as populações nordestinas são em geral subnutridas, e consequentemente vulneradas no seu estado sanitário, razão pelo qual devem ser promovidos locais referentes a problemas sanitários e de assistência à maternidade e infância, para que se possa contar com gente sadia para os empreendimentos visados no Nordeste;

d) terá necessidade de elaboração imediata de um plano de trabalho que permita assegurar aos migrantes nordestinos uma assistência humana condigna, sobretudo aparelhando os postos de migração e modificando a orientação das hospedarias para que venham a cumprir adequadamente suas finalidades, uma vez que são ainda precárias as condições de assistência, em particular quanto ao problema de transporte e colocação.

5. Afirmamos a esperança de ver o problema da reforma agrária no Nordeste equacionar-se oportunamente com salvaguarda, dentre outros, dos seguintes princípios: 
a) apoio técnico e financeiro do Poder Público a particulares desejosos de dar um destino social mais adequado às próprias terras, através de planos que importem na gradativa promoção de famílias rurais, abrindo assim acesso à propriedade das glebas;

b) exemplo do Poder Público de adoção de planos racionais relativos a terras de sua propriedade, mediante formas de colonização de tipo novo, em que atuem Grupos de Trabalho de que participem Órgãos como o M.A., o INIC, o DNOCS, o BMB, o SSR, e a ANCAR, e em que o objetivo também seja o gradativo acesso à propriedade por partes das famílias selecionadas;

c) maior estabilidade do trabalhador rural à terra que cultive, mediante o estimulo à adoção de contratos legais de arrendamento e de parceria agrícola, em bases de justiça social;

d) em casos especiais, e tendo em vista ampliar e diversificar o parque de produção de gêneros alimentícios para o abastecimento da população nordestina ou visando a outros fins de interesse social, aquisição, pelo Poder Público, mediante preços justos, de terras da zona úmida ou valorizadas por obras dos Poderes Públicos, quando improdutivas ou utilizadas com exclusiva finalidade especulativa;

e) cuidado extremo em evitar açodamentos demagógicos, paixão partidária, personalismos, de vez que se trata de matéria delicada e facilmente explosiva, cujo tratamento legal, partindo dos estudos da Comissão Nacional de Política Agrária, deve ser confiado a grupo interpartidário especialmente constituído para esse fim.

6. Afirmamos o desejo de ver o planejamento regional a longo termo completado por atendimentos locais imediatos, inadiáveis, por corresponderem a justos e profundos anseios do povo e por facilitarem a aceitação do Nordeste como um todo.

7. Afirmamos o anseio de assistir, por ocasião do próximo ano eleitoral, à demonstração de maturidade cívica por parte de 
todos os Partidos Políticos, dos quais esperamos a colaboração da Operação Nordeste fora e acima das lutas partidárias.

8. Afirmamos a angustiada esperança de ver para sempre banido do Nordeste, máxime em horas de calamidade meteorológica, a desonestidade de aproveitadores da miséria e da fome, pecado que brada aos céus.

9. Afirmamos a nossa confiança em que o Governo Federal poupe e libere, num momento necessário, as verbas dos órgãos públicos destinados ao Nordeste, evitando assim a descontinuidade dos serviços programados.

10. Afirmamos que não seria possível conseguir maior rendimento e rapidez na atuação do Ministério da Agricultura no Nordeste sem dar a este órgão uma estrutura atualizada, maior soma de recursos e flexibilidade na sua aplicação, bem assim condições de ampliação de seus quadros técnicos e valorização desses profissionais.

11. Afirmamos o proposito de oferecer ao Governo a desinteressada colaboração da Igreja, na Região, através de todas e de cada uma de suas Circunscrições Eclesiásticas, à implantação gradual e progressiva da Operação Nordeste, demonstrando mais uma vez a presença da Igreja na solução dos grandes problemas humanos.

\section{II - Conclusões}

Passados 3 anos do I Encontro dos Bispos do Nordeste, demos um balanço criterioso nos planos de ação decorrentes de Campina Grande e chegamos às seguintes Conclusões que, em sua parte positiva, são dadas, antes de tudo, ao apoio absoluto que lhes deu o Excelentíssimo Presidente da República, Dr. Juscelino Kubitschek, através de seu Gabinete Civil (e somos gratíssimos ao Dr. Vitor Nunes Leal e ao seu Assessor Técnico Dr. Francisco Monteiro Filho):

\section{A) Planos que vão muito bem}

a) Decreto n 39.287 - Dispõe sobre as medidas necessárias ao desenvolvimento econômico dos Vales Secos de Baixo Piranhas e Apodi, no Estado do Rio Grande do Norte. 
Na região do Aço e Apodi foram inaugurados os seguintes melhoramentos: 153 casas populares, como parte de um programa de 500 habitações; 10 maternidades; 12 postos de puericultura; 1 conjunto educacional com cerca de $400 \mathrm{~m}^{2}$ de cobertura, abrangendo escola normal rural, escola de comercio e escola de economia domestica; rodovia Mossoró-Areia Branca; patrulha de irrigação no Vale do Açu; grupo gerador de energia elétrica na cidade de Açu e oficinas de reparos de máquinas em Mossoró. Mais de 200 moto-bombas já estão irrigando 1.200 hectares nos Vales do Açu e Apodi e outras 200 estão sendo instaladas, o que assegurará a irrigação antes do fim do ano, de 2.000 hectares.

Nos vales úmidos um núcleo de produção (dois outros se acham em andamento) consegue resultados estonteantes.

Vai iniciar-se a construção de uma rede de armazéns de tipo médio para estocagem e financiamento da produção de cereais na zona oeste do Estado.

Foi instalada e inaugurada uma Emissora de Educação Rural, com o funcionamento de quase 300 escolas dotadas de rádios cativos.

À frente desses trabalhos se acham D. Eugenio Sales e D. Eliseu Mendes. O maior prodígio foi obter o perfeito entrosamento de 11 Órgãos Federais que viviam desarticulados.

b) Decreto $n^{\circ} 39.295$ - Dispõe sobre as medidas necessárias ao desenvolvimento da criação de gado e da indústria leiteira nos Estados da Paraíba e Alagoas.

Para cumprimento deste Decreto foram criados dois Grupos de Trabalho: o Grupo Cariri (articulação de 5 Órgãos Federais que viviam desarticulados), que se impôs à confiança geral pelo funcionamento efetivo do crédito rural supervisionado, tendo como consequências a construção de silos para forragens; a plantação de sorgo, de palma e de algaroba; financiamento de gado; e sobretudo a perfuração de poços tubulares com resultados capazes de modificar a economia da pecuária local.

O Grupo Alagoas (Palmeira dos Índios) está começando a obter resultados na linha do Grupo Cariri.

A alma desses trabalhos é D. Otavio Aguiar, bispo de Campina Grande. 
c) Decreto no 39.288 - Dispõe sobre as medidas necessárias ao máximo aproveitamento do Açude Curema e suas áreas de influencia.

Foi construído o açude Mãe d'Água, em comunicação com o de Curema (670.000.000 $\mathrm{m}^{3}$ de água); foi concluída a casa de força para aproveitamento hidrelétrico do Açude Curema e da primeira usina desse sistema; foi concluída a linha de transmissão e distribuição para as cidades de Curema, Piancó, Pombal e Sousa. A linha de Patos, em andamento.

Serviços de abastecimento de água: concluído em Piancó; em fase final em Sousa; iniciados em Patos, Cajazeiras, Misericórdias e Princesa.

Conclusão do estudo e elaboração do Projeto para exportação da água do sistema Curema-Mãe d'Água para as várzeas de Sousa.

Foi concluída a retificação da rodovia Central de Paraíba, estando pronta para o recebimento da camada de asfalto.

d) Decreto no 39.389 - Dispõe sobre as medidas necessárias ao escoamento regular da produção das jazidas de fosfato de Olinda.

O Projeto foi divulgado em duas partes: ligação ferroviária do trecho de $18 \mathrm{~km}$ entre Camaragibe e o Forno de Cal (estão concluídos 7 quilômetros e em pleno andamento os 11 restantes); ampliação do porto de Recife. O prolongamento do cais será da ordem de 470m e os trabalhos em pleno andamento deverão estar concluídos em setembro de 1960.

e) Decreto no 39.299 - Dispõe sobre o abastecimento de água para Campina Grande.

Foi concluído em tempo recorde o Açude Boqueira, de Cabaceiras, e inteiramente construída uma adutora de $40 \mathrm{~km}$ e desnível de quase 500m com fornecimento de 21.600.000 litros de água diários à cidade.

\section{B) Planos em Andamento}

a)Decreto no 39.285 - Dispõe sobre a instalação de um núcleo colonial destinado ao abastecimento de Fortaleza.

Vencidas numerosas dificuldades iniciais, encontra-se em grande atividade o trabalho de instalação do Núcleo Colonial Pio XII: 1.400 hectares, dispondo de um grande açude e dois menores, com capacidade de 
$10.000 .000 \mathrm{~m}^{3}$ de água; serão irrigados 300 hectares e construídas casas nos lotes já demarcados.

Em breve teremos os primeiros fornecimentos de verduras, frutas, aves e ovos à capital cearense.

Foi assinado convênio para a construção imediata de 50 casas para colombos, estando já depositada no BNB a quantia de Cr\$4.698.000,00 para atendimento das despesas.

b) Decreto no 39.298 - Dispõe sobre o auxilio financeiro ou prêmio para a instalação de armazéns destinados a cereais e assemelhados no Polígonos das Secas.

Ate junho do ano passado foram concedidos prêmios no valor de Cr\$ 67.400.000,00.

c) Decreto no 39.296 - Dispõe sobre as medidas necessárias à produção e distribuição em tempo útil de sementes selecionadas, mudas e enxertos destinados à lavoura nordestina.

Em 1958 foram distribuídas sementes de cereais e algodão herbário no valor de Cr\$ 6.170.000,00. No corrente ano, para cumprimento do Decreto, foram despendidos Cr\$29.600.000,00.

As Dioceses cooperaram com a Divisão de Formento Agrícola na distribuição de sementes no Nordeste.

Surgiu, neste Encontro, proposta relativa a este Decreto.

d) Decreto no 39.284 - Dispõe sobre a instalação de um núcleo colonial no Vale do Rio Paraíba.

D. Avelar Brandão, Arcebispo de Teresina, julgou mais indicada a localização do núcleo à margem do rio Gurgueia, o que exigiu novo ato de Poder Público (Decreto no 45.219, de 15-1-1959). O Núcleo do Gurgueia se acha em plena construção.

Neste II Encontro, como se verá no capítulo de Sugestões, surgiu propostas de dinamização e ampliação desse Núcleo.

e) Decreto no 39.290 - Dispõe sobre a instalação de um núcleo colonial destinado ao abastecimento de Recife.

Foi adquirida a Fazenda e estão em construção 42 casas para colonos. O núcleo, a ser inaugurado em menos de um ano, concorrerá para a melhoria do abastecimento da Capital pernambucana. Surgiu, no presente Encontro, proposta de dinamização e ampliação deste plano. 


\section{C) Planos em vias de Funcionamento}

a)Decreto no 39.283 - Construção do porto de Itaqui, Estado do Maranhão.

Já foi um grande passo rescindir o contrato com a firma inidônea que deveria ter concluído o porto em 1956. Foi aberta nova concorrência.

b)Decreto no 39.292 - Dispõe sobre a instalação de postos de imigração nos Estados de Pernambuco, Sergipe e Bahia.

No roteiro das migrações dos nordestinos para o sul do país foram instalados postos em Petrolina, Propriá, Aracaju, Feira de Sant'Ana e Mapele. Novos postos estão sendo criados para a complementação da rede que se tem em vista mas muito há por se fazer quanto ao atendimento dos chamados $<<$ paus-de-arara $>>$, nossos irmãos nordestinos que fogem da seca. Há, principalmente, falta de recursos para manutenção.

c)Decreto no 39.293 - Dispõe sobre a instalação de 350 famílias nos núcleos coloniais localizados no Estado da Bahia.

Foram escolhidos os núcleos de Ituberá, Andaraí, Una e Porto Seguro. Neles já foram construídas 90 casas e cerca de 160 lotes aguardam famílias selecionadas pela ANCAR. Estuda-se um programa de cultura intensiva de seringueira nesses núcleos.

d)Decreto n $^{\circ} 39.282$ - Dispõe sobre a instalação de núcleo colonial no Vale do Rio Mearim, com capacidade para 2.000 famílias.

D. José Delgado, Arcebispo de São Luís, concordou com o aproveitamento do atual núcleo de Barra do Corda $<<$ desde que o INIC instale concomitantemente um posto de triagem em Coroatá, ponto de passagem obrigatória dos nordestinos que se estabelecem no Maranhão. O Posto já esta sendo instalado. O aproveitamento total do núcleo dependerá ainda da conclusão da Hidroelétrica de Barra do Corda. Já se encontra no local o material elétrico a ser instalado.

e)Decreto no 39.294 - Dispõe sobre a construção de casas para trabalhadores nordestinos.

Já foram construídas mais de 300 habitações rurais. Estão sendo edificadas casas para colonos no núcleo de abastecimento do Recife e nos próximos dias será iniciada a construção no núcleo de Fortaleza. 


\section{D) Planos Com Dificuldades De Andamento}

a)Decreto no 39.286 - Dispõe sobre as medidas necessárias ao desenvolvimento da produção do sal e aperfeiçoamento de seus métodos na área que interessa ao porto de Areia Branca, Rio Grande do Norte.

O plano do Porto Teleférico, importando na mecanização das salinas, está em risco de não se concretizar por falta de entendimento entre os salineiros da região, isto é, Mossoró, Areia Branca e Grossos. Surgiu, porém, o interesse de maior grupo produtor de sal do Rio Grande do Norte pela construção de um porto continental em Macáu. Na área de Areia Branca já se havia realizado a prospecção das torres num percurso de 7 quilômetros. Entretanto, segundo informações recentes, está havendo um movimento de reorganização do Grupo de Areia Branca objetivando o reinício dos trabalhos do Porto Teleférico.

b)Decreto $n^{\circ} 39.291$ - Dispõe sobre a instalação de 200 famílias na Colônia Pindorama, Alagoas.

Tem havido dificuldades de entrosamento entre a Coordenação Geral dos planos decorrentes do Encontro de Campina Grande e a direção da Colônia de Pindorama.

c)Decreto no 39.297 - Dispõe sobre as medidas necessárias ao desenvolvimento da indústria animal da Bahia e no Nordeste de Minas Gerais.

Trata-se de tarefa de grande amplitude, não só pela imensa área abrengida mas também pelo montante dos investimentos necessários à sua execução. Foram feitos estudos concretos quanto à Bahia e Nordeste de Minas.

Neste II Encontro surgiu uma proposta, divulgada no local adequado, de revigoramento do Decreto no tocante ao Nordeste de Minas.

\section{III - Sugestões}

Além da formulação de princípios gerais que devem informar o processo de planejamento e execução dos programas de desenvolvimento do Nordeste Brasileiro, os Grupos de Estudo, em que se dividiu o II Encontro de Bispos do Nordeste, formularam indicações, votos e recomendas gerais. 
Estas indicações e recomendações poderão constituir subsídio útil para a formulação de Projetos que possam ou devam enquadrar-se no Plano Diretor da OPENO. Em outros casos, certas medidas administrativas e providências poderão resultar em simples programas de trabalho.

As proposições podem ser classificadas em 3 grupos, a saber:

- Indicações que, emanadas do Encontro de Campina Grande, sugerem revisões, revitalização, ampliação ou nova formulação;

- Proposições específicas que deverão constituir subsídio para projetos ou programas de ação futura;

- Indicações gerais, recomendações ou votos.

Quer nos Projetos cuja revisão se pede ou nas proposições que deram lugar a novos Projetos, a Autoridade Diocesana em cujo território se localizar a iniciativa estaria disposta a vincular-se aos Grupos de Trabalho a serem constituídos pelo Governo Federal.

No futuro imediato, os Projetos devem continuara a ser coordenados pelo Gabinete Civil da Presidência da República. Uma vez funcionando a SUDENO, os Projetos e Programas que se criarem, passariam oportunamente a com ela articular-se, segundo os critérios gerais estabelecidos pelo Plano Oficial para o Nordeste.

As proposições são aqui apresentadas simplesmente através das respectivas emendas: à Exma. Presidência da República será entregue a formulação mais completa de cada proposição.

\section{A) Educação de base e promoção operária}

1. Estabelecimento de medidas de financiamento para um Programa de Educação de Base através de Escolas Radiofônicas para o Nordeste.

2. Programa de Educação de Base através de Escolas Radiofônicas em Sergipe.

3. Programa de educação de base no Norte do Estado de Alagoas através de escolas radiofônicas, missão rural e centro de treinamento.

4. Programa Piloto de desenvolvimento de Artezanato - Rio Grande do Norte. 
5. Curso de Líderes Rurais em Cooperativismo da Missão InterMunicipal Rural Arquidiocesana, do Maranhão.

6. Escola de Pesca em Maceió.

\section{B) Estrutura Agrária}

1. Reativação do Núcleo de Abastecimento do Recife, previsto no Decreto no 39.290.

2. Projeto de desenvolvimento social e agropecuário Montes Claros, Minas Gerais.

3. Incentivo ao desenvolvimento econômico do Vale do Rio Carás (Ceará).

4. Experiências de colonização do Maranhão, em terras oferecidas pela Igreja.

5. Aproveitamento da bacia leiteira do Rio Acaraú, no Ceará.

6. Valorização econômica e social do Vale do Jaguaribe, no Ceará.

7. Plano de desenvolvimento da bacia hidrográfica do Rio Mamanguape, na Paraíba.

8. Criação de uma Fundação para o aproveitamento dos veles úmidos do Rio Grande do Norte.

9. Criação de um Grupo de Trabalho para irrigação em Alagoas, aproveitando as águas do $\mathrm{S}$. Francisco.

10. Recuperação do Vale de Marituba - Alagoas.

11. Colonização das Fazendas $<<$ Seuca $>>$ e $<<$ Genipapo $>>$ em Alagoas.

\section{C) Agricultura e Abastecimento}

1. Abastecimento de água da cidade de Montes Claros, Minas Gerias.

2. Incremento da pecuária, das pequenas indústrias rurais e caseiras, bem como fomento da cultura do algodão mocó.

3. Grupo de Trabalho para promover a intensificação dos trabalhos de colonização no núcleo colonial do Gurgueia, no Piauí, ampliando os trabalhos para o fomento agropecuário, bem estar e extensão rural. 
4. Grupo de Trabalho para o desenvolvimento agrícola de determinadas áreas no sentido de fornecimento de suprimentos alimentares a Aracajú.

5. Grupo de Trabalho para incentivar o desenvolvimento agroindustrial dos vales úmidos do Estado de Sergipe.

6. Grupo de Trabalho para proporcionara expansão de forrageiras nativas ou introduzíveis, com destaque da algaroba, tendo em vista a necessidade de alimentar o gado, de proteger o solo.

7. Criação de um Grupo de Trabalho para a construção de uma rede de armazéns e silos no Estado de Sergipe.

8. Grupo de Trabalho para o desenvolvimento da agropecuária no agreste pernambucano.

9. Amplição de termos do Decreto 39.287 no sentido de permitir o acesso aos pequenos agricultores de material de revenda para o uso próprio.

10. Grupo de Trabalho para o aproveitamento racional, inclusive para fromento de industrialização dos mangues do Maranhão.

\section{D) Saúde, Maternidade e Infância}

1. Programa de campanha sanitária através de centros educativos e de Assistência-médico-sanitária e à maternidade e infância.

2. Incentivo à campanha de combate ao tracoma no Cariri cearense.

3. Instalação de 10 unidades polivalentes de saúde: serviços de ambulatório, maternidade e pequena enfermaria - em Pernambuco.

4. Cooperação de Rede existente hospitalar e materno-infântil das 3 Dioceses do Rio Grande do Norte.

\section{E) Migrações Internas}

1. Plano de trabalho que permita assegurar os migrantes nordestinos uma assistência humana e condigna, em todas as fases do deslocamento e por todas as vias utilizadas. 
2. Transformações das atuais Hospedarias de Migrantes sediadas em capitais em Hospedarias Rurais, sem prejuízo dos programas de colonização.

3. Ampliação das atividades dos Postos de Migração de modo que sejam atendidos também os migrantes por via rodoviária.

4. Incorporação dos Postos de Migração de Teresina e de Coroatá à rede de Postos criados por sugestão do Encontro de Campina Grande, assegurando-lhes os meios financeiros e humanos necessários ao seu pleno funcionamento.

\section{IV - Votos}

Em Anexo à Proposições que serão entregue à Exma. Presidência da República, seguirão os votos numerosos apresentados, discutidos e aprovados nos Grupos de Trabalho deste Encontro.

Nosso II Encontro, com o I, se realiza em pleno mês de maio. De novo entregamos à Santíssima Virgem Maria, para que Ela tudo leve ao Senhor, nossos anseios, nossas esperanças, e sobretudo, nosso imenso desejo de servir a Deus e ao próximo.

Natal, 26 de maio de 1959.

(Seguem-se as assinaturas dos 22 Bispos presentes). 